\title{
Recent Progress on Tailoring and Modification of Membranes for Membrane Distillation: A Review
}

\author{
Nur Fazira Sufianasuri \& Nur Hashimah Alias* \\ Department of Oil and Gas Engineering, School of Chemical Engineering, College of \\ Engineering, Universiti Teknologi MARA, 40450 Shah Alam, Selangor, Malaysia \\ Submitted: 30/9/2021. Revised edition: 10/11/2021. Accepted: 11/11/2021. Available online: 15/11/2021
}

\begin{abstract}
Membrane distillation (MD) has gained the interest of many researchers since it is a promising method for the separation and purification process. Membrane distillation (MD) is a non-isothermal separation process in which differential vapor pressure between porous hydrophobic membrane surfaces acts as a driving factor. A hydrophobic membrane is used in the application of MD, which permits only the passage of vapor produced on the feed side through its pores to the permeate side. One of the most significant obstacles to the commercialisation of the MD method is a lack of appropriate membranes for the process. On the other hand, conventional hydrophobic membranes are subjected to rapid wetting and severe fouling, mainly when low surface tension compounds are present in saline water, resulting in decreased MD performance. In recent decades, MD membranes have received exceptional scientific interest, with substantial progress being made in the design and production of MD membranes appropriate for use in many applications. This review gives a comprehensive overview of recent research developments in the tailoring morphological structure of hydrophobic membranes, emphasising advancements in the fabrication and modification of membranes towards exhibiting high efficiency in the MD process. In addition, the critical morphology characteristics, mainly surface roughness, wettability, and water contact angle, are analysed. Finally, the challenges faced and future research direction is highlighted.
\end{abstract}

Keywords: Membrane distillation, tailoring, modification, characterisation, recent progress, review

\subsection{OVERVIEW ON MEMBRANE DISTILLATION}

The rapid growth of metropolitan areas along with an increasing worldwide population are the driving factors that contribute to the demand for sufficient and potable water supplies [1]. According to the global population clock, the global population has surpassed 7 billion and is estimated to rise to 10 billion by 2050 [2-3]. Therefore, a key challenge for the emerging countries of the globe would be the availability of safe drinking water. To overcome the water scarcity issue, enhancing the efficiency and affordability of water treatment is a critical component that needs to be emphasised [4].

\subsection{Fundamental on Membrane Distillation}

Membrane technology has experienced a significant increase in popularity over the last few years as one of the water treatment methods. The membrane technology has great potential in water treatment due to its

\footnotetext{
* Corresponding to: Nur Hashimah Alias (email: nurhashimah@uitm.edu.my)

DOI: https://doi.org/10.11113/amst.v25n3.228
} 
substantial decrease in equipment size, energy consumption, and inexpensive capital cost [5-7]. Therefore, membrane distillation, which was first presented six decades ago, can be widely employed in commercial applications [8,9], although it is still in the research stages [8-9]. Membrane distillation is a thermally-driven separation process that comprises a porous hydrophobic membrane that allows the vapors produced by the feed liquid to flow through to the permeate side [9-11]. Figure 1 illustrates the membrane distillation process. The hydrophobic membrane is the critical component in the separation process. It prepares the medium for the vapor generated on the feed side to penetrate it and act as a barrier to prevent the liquid water from being transferred directly to the other side [12-14]. A variety of configurations with distinct thermal efficiency and mass transfer trade-offs can be a reference to assist membrane distillation and induce the vapor pressure difference across the membrane $[11,15]$. The separation performance and cost of operation are greatly affected by the MD configuration. Numerous research teams have proposed innovative designs with increased energy efficiency, better permeate flux, or a reduced footprint [16-18]. These configurations include direct contact membrane distillation (DCMD), air gap membrane distillation (AGMD), vacuum membrane distillation (VMD), and sweep gas membrane distillation (SGMD). In DCMD, the permeate side of the membrane is in contact with the cooled draw aqueous solution, which causes the mass transfer to be enhanced, resulting in greater productivity $[15,19]$. DCMD is the most simplified arrangement and has been extensively explored in the literature and laboratories for desalination and concentration of aqueous solutions [14,20-22].

For AGMD, a thin air gap is created between the membrane and the condensation surface. The membranes and the air gap allow the evaporated volatile molecules to flow through and then condense on the cool surface [25]. Typical AGMD systems have lower fluxes than DCMD or VMD configurations due to the high vapor transport resistance provided by the air gap [14, 24]. With VMD configuration, the permeate side of the membrane module is subjected to vacuum pressure [17]. The applied vacuum is lower than the saturation pressure of volatile molecules in the feed solution to produce the necessary driving force $[25,26]$. In SGMD, a cold, inert gas, also known as a sweep gas, is drawn over the permeate channel, collecting vapour molecules accumulated on the membrane's surface as it moves along [27, 28]. Membranes with low mass transfer resistance and high heat transfer resistance are preferable for increasing the driving force in MD and, subsequently, achieving a high permeate flux [31]. The performance of the membrane varies greatly depending on the inherent characteristics of membrane materials [32]. The surface roughness, wettability, and water contact angle are several characteristics that describe the morphological structure of a membrane used in membrane distillation. The water contact angle and wettability of the membrane are known to be correlated with the roughness parameter. In addition, the measure of the static water contact angle is increased as the surface is roughened [31, 32]. 

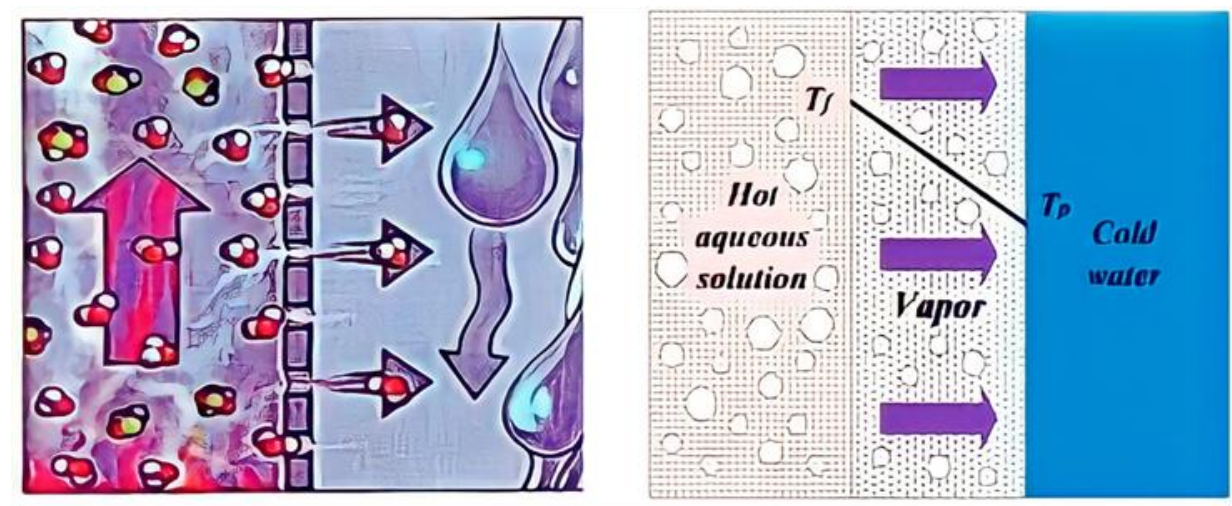

\section{Hydrophobic \\ Membrane}

Figure 1 Illustration of membrane distillation process [33]

\subsection{Issues on Membrane Distillation}

In membrane distillation, the membrane is susceptible to fouling and wetting issues, both of which can negatively influence the system's overall performance. Dissolving low surface tension compounds and organic components in feed water is the primary cause of wetting, resulting in decreased water output [36]. Therefore, numerous global scientific research has stressed the necessity for more selective membrane fabrication to overcome these constraints. Many efforts have been made to develop a superhydrophobic membrane by utilising low-surface energy materials and constructing hierarchical microstructures [37]. In long-term MD operation, membranes with a superhydrophobic surface tend to have better flux and lesser flux reduction than membranes with a hydrophobic surface. This is due to the fact that they have significantly stronger wetting resistance and self-cleaning characteristics [38]. Although the superhydrophobic membranes have increased the wetting resistance considerably, the membrane's intact oleophilic features still reduce the fouling resistance due to the hydrophobic-hydrophobic interaction between the membranes and organic foulants in the feed water [37, 38]. Apart from the superhydrophobic membrane, an omniphobic membrane characterised as water, and low-surface tension agent repellent has been developed and applied in the membrane distillation process. However, omniphobic membranes are still susceptible to fouling issues as a result of hydrophobic foulants such as oil droplets on the membrane surface $[8,17]$. The research discovered that a membrane with a unique wettability feature was the most effective fouling and wetting resistance improvement $[36,40]$. As a result, a membrane known as the Janus membrane with an asymmetric wettability has been developed and designed to address both membrane wetting and fouling problems concurrently. In addition, oleophobicity underwater may resist oil droplets and prevent oil fouling in the Janus membrane, which contains a thin hydrophilic layer that is hydrated with water. Thus, there is a lot of innovation has been made to improve membrane distillation performance. In this paper, we aim to review the recent development on the morphological structure of the membrane for efficient membrane distillation. 


\subsection{FABRICATION OF MEMBRANES FOR MEMBRANE DISTILLATION}

For the past three decades, a commercially available membrane precisely optimised for MD operations has yet to be developed [19-21]. This is primarily because most of the early works focused solely on the theoretical analysis of the MD process. However, there have been significant advancements in fabrication technology in recent years, developing new membranes with enhanced surface wettability that may be used in the MD process. The fabrication of MD membranes may be carried out using a variety of operations such as sintering, phase inversion, stretching, template leaching, electrospinning, and tracketching. The chosen method for the fabrication of membrane depends on the materials and the design shape of the membrane [46].

\subsection{Polymeric Membranes}

A polymeric membrane is an organic membrane synthesised from an organic synthetic polymer that possesses hydrophobic surfaces such as polyvinylidene fluoride (PVDF), polytetrafluoroethylene (PTFE), and polypropylene (PP). This membrane is mainly utilised in the membrane distillation process as it offers a feature such as versatility and low thermal conductivity $\quad\left(0.1-0.5 \quad \mathrm{~W} \cdot \mathrm{m}^{-1} \cdot \mathrm{K}^{-1}\right)$ [47]. For the fabrication of polymeric membranes, the most widely utilised methods include phase inversion, interfacial polymerisation, stretching, track-etching, and electrospinning [4, 33, 48-56]. Phase inversion is the most widely used method to prepare a membrane for the membrane distillation process. In this method, the mixing process converts the liquid phase homogenous solution to the solid phase. There are various types of phase inversion techniques, including Nonsolvent induced phase separation (NIPS), Thermally induced phase separation (TIPS), and vapor induced phase separation (VIPS). However, due to the mild processing conditions and the easiness with which membrane shape can be controlled, NIPS is the most often used phase inversion technique for producing hydrophobic membranes [32]. Polymer, solvent, and non-solvent are the crucial components in the NIPS process [57]. The process starts with forming an initial homogenous solution by dissolving a polymer in its solvent. Then, the phase separation occurs where the solvent of the homogenous solution is exchanged into the non-solvent resulting in a polymer residue that forms the membrane [58]. Nejati et al. [59] synthesised a high-performance hydrophobic membrane using a PVDF dissolved in triethyl phosphate (TEP) as a casting solution. The development of a hydrophobic membrane with an asymmetric structure is the consequence of the non-solventinduced phase separation of polyvinylidene fluoride (PVDF) in triethyl phosphate (TEP). The high surface porosity and roughness of the top surface attributed to the increase in the concentration of a soft coagulation agent (2-propanol) in the coagulation bath was observed since the roughness of the top surface of the membranes was significantly dependent on the amount of 2-propanol present. As a result of the considerable increase in surface roughness, the surface contact angle has also increased considerably. As a result, the performance of the MD membranes in terms of water vapor flow varied substantially depending on the orientation of the membranes.

It was discovered that the membrane porosity and thickness substantially impacted the water vapor 
flow. When the membrane thickness was lowered while the porosity was increased, a rise in vapor flow was observed. Furthermore, due to the stabilisation of airgaps at the liquidsolid interface, hydrophobicity increases. Therefore, increasing the stability of the air gaps will improve MD performance by decreasing the likelihood of partial wetting of the membranes. Munirasu et al. [60] have synthesised a highly porous and intrinsically superhydrophobic PVDF membrane by utilising a phase inversion method with alcohols including methanol and ethanol as the non-solvent on non-woven support. From the characterisation of the membrane, the surface and crosssectional SEM analyses of the PVDF membrane revealed that the morphology of the membrane is a sponge-like interconnected fibrous structure across the membrane with no selective top layer.

In comparison to the PVDF membrane on a support, the superhydrophobic PVDF membrane demonstrated comparatively high flux with good salt rejection, and the longterm MD measurements over a time span of more than a week revealed a steady flux after initial stabilisation. Additionally, the water contact angle of PVDF membranes produced using methanol as the non-solvent is around $164^{\circ}$. Because of the lack of a selective top layer and the presence of a spongelike linked fibrous structure throughout, it is a promising material for studying surface wetting/nonwetting behavior. Another study by Thomas et al. [61] has fabricated PVDF membrane with sponge-like structures. The structure was achieved due to the delay in the rate of liquid-liquid de-mixing of the polymer, where the immersion time was strictly controlled during the coagulation step. The membrane was fabricated via the NIPS techniques without pore-forming additives for the MD application. Table 1 summarises the fabrication techniques for polymeric membranes.

Table 1 Summary of fabrication techniques used for polymeric membrane

\begin{tabular}{|c|c|c|c|c|}
\hline Polymer & Fabrication & $\begin{array}{l}\text { Water contact angle } \\
\left({ }^{\circ}\right)\end{array}$ & $\begin{array}{l}\text { Application and } \\
\text { configuration }\end{array}$ & Ref. \\
\hline PVDF & NIPS & $125 \pm 2$ & MD/DCMD & [53] \\
\hline PVDF & Phase inversion & 164 & MD/DCMD & [54] \\
\hline PVDF & NIPS & $100-127$ & MD & [55] \\
\hline
\end{tabular}

\subsection{Ceramic Membranes}

Since the beginning of the previous decade, ceramic membranes have received growing interest in various separation applications, including industrial wastewater and drinking water treatment, desalination, and gas separation [62]. Due to their superior mechanical, chemical, and thermal stability, the ceramic membrane is more resilient toward severe operating conditions than polymeric membranes
[57, 58]. Phase inversion and sintering have recently been utilised to fabricate various ceramic membranes, including flat sheets $[59,60]$, hollow fiber [6165], and tubular [62]. It has been demonstrated that the combined phase inversion and sintering method is a promising method for the production of ceramic membranes compared to traditional methods [72]. In this method, the asymmetric ceramic membranes are produced in a single fabrication step as only one heat 
treatment is necessary [73]. This approach involves preparing a suspension of ceramic particles, an organic solvent, a polymer binder, and water. Due to the phase inversion caused by the exchange between solvent and non-solvent, the ceramic particles are immobilised through spinning or casting, depending on the shape. Finally, all organics are removed from the membrane precursors, and the membrane's mechanical properties are improved [74]. Currently, alumina is employed in the majority of commercial ceramic membranes. However, high sintering temperatures (about $1500^{\circ} \mathrm{C}$ ) are required to provide appropriate porosity and mechanical strength in these materials. The requirement for pure alumina powder and a high sintering temperature leads to increased manufacturing costs, which is the most significant disadvantage of ceramic membrane technology. However, a great effort of research has been made on developing a low-cost hollow fiber ceramic membrane made of natural mineral powders and other inorganic materials [75].
A low-cost zeolite-based Horizontal Fuel Conditioning Module (HFCM) has been fabricated by Adam et al. [76] using a phase inversion-based sintering technique. Figure 2 depicts the impact of sintering temperature on the morphology behavior of the membrane. It has been shown that a highly porous membrane with a loosely packed fine structure was obtained at the lowest sintering temperatures compared to other sintering temperatures. As the temperature rises, the structure of HFCM becomes less porous, and the grains are densely packed. In terms of the contact angle, the contact angle was increased from less than $5^{\circ}$ to more than $50^{\circ}$ due to the dehydration of the ceramic membrane. The membrane surface shows superhydrophobic features at a low temperature which was attributed to the presence of $\mathrm{OH}$ groups [77]. As the temperature rises, the $\mathrm{OH}$ group is dehydrated resulted in more closely packed ceramic particles. In this condition, the ceramic membrane possesses a hydrophobic characteristic.
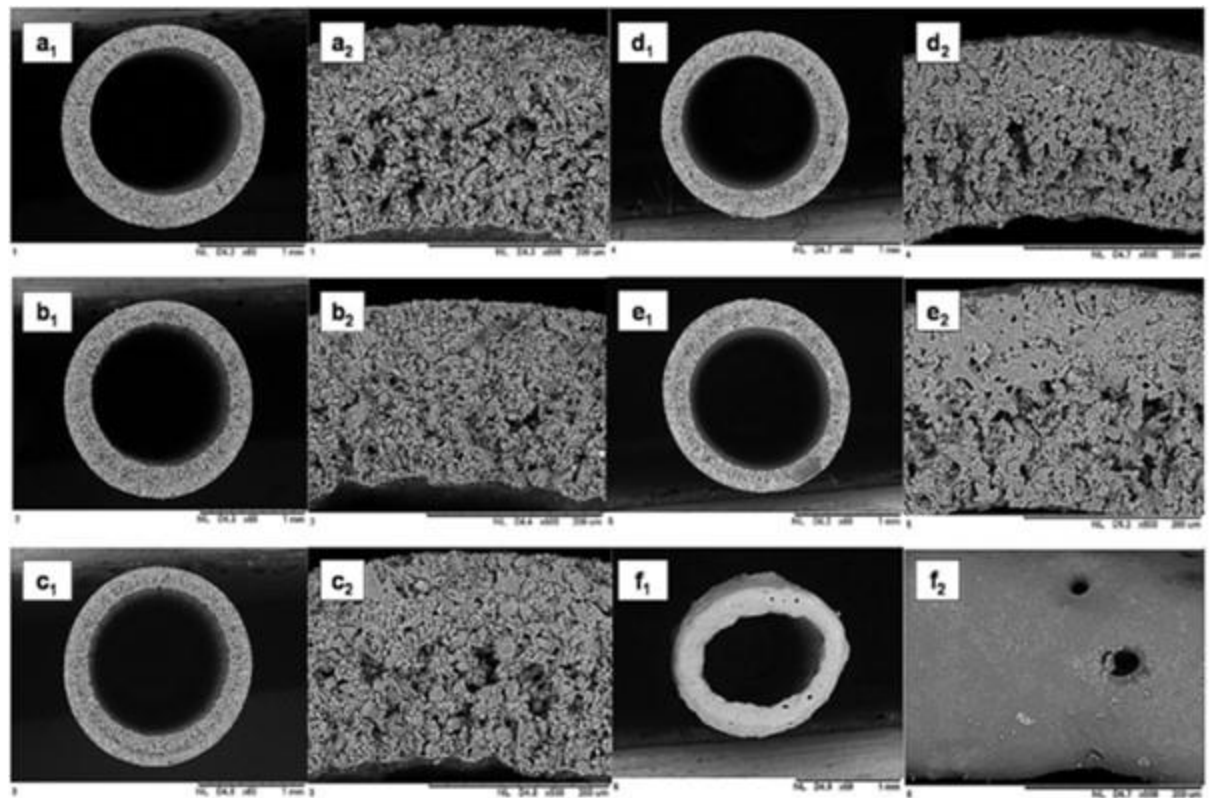

Figure 2 Cross-sectional SEM images of fibre 7 sintered at different temperature; (a) $900^{\circ} \mathrm{C}$, (b) $950^{\circ} \mathrm{C}$, (c) $1000^{\circ} \mathrm{C}$, (d) $1050^{\circ} \mathrm{C}$, (e) $1100^{\circ} \mathrm{C}$, and (f) $1150^{\circ} \mathrm{C}$; (1) overall cross -section, (2) zoom at the voids [70] 
Another study of ceramic membrane fabrication has been accomplished by Bandar et al. [64]. This study fabricated a compelling novel membrane by integrating an inorganic substance (red clay) with liquid TEOS, ammonia, and sodium alginate powder to produce a porous distribution inside the red clay membrane. The average pore size of the constructed membrane was $33 \mathrm{~nm}$, indicating that ultramembrane distillation was accomplished without the need for a coating layer. Continuous water desalination experiments revealed that the membrane maintained its performance for four $h$, with the $16.5 \%$ flux decrement after 10 hours attributed to fouling caused by the presence of salts and suspended particles in the solution. The percentages of salt ions deposited on the membrane by well water were determined to be greater than $80 \%$, and fouling deposits were easily eliminated by flushing with deionised water (DI) water. The membrane's initial performance (water flow of 30.13 $\mathrm{kg} / \mathrm{m}^{2} \mathrm{~h}$ ) and water conductivity of 1 $\mathrm{S} / \mathrm{cm}$ ) was recovered after a three $\mathrm{h}$ VMD test with DI water. In recent studies by Peng et al. [78], the ceramic membrane with anti-fouling PTFE coating was fabricated by vacuum filtration method. In this work, the outer surface of an alumina membrane substrate was disseminated, coated, and thermally sintered by using PTFE nanoparticles to form a resilient defectfree layer with hydrophobicity and a low friction coefficient. The PTFE coating acted as a protective barrier, reducing the adhesion of foulants due to their low surface energy, smooth surface, and low friction coefficient. Table 2 summarises the fabrication techniques for ceramic membranes.

Table 2 Summary of fabrication techniques used for polymeric membrane

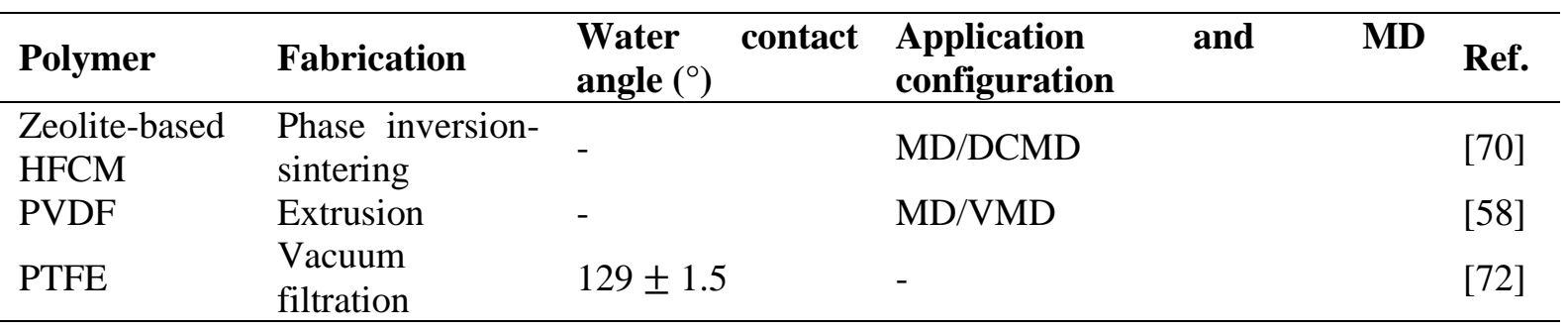

\subsection{Composite Membranes}

Several hydrophobic surface modification techniques, including surface coating, grafting, mixing, and copolymerisation, can remove or decrease membrane wetting, a wellknown MD process difficulty caused by a lack of hydrophobicity [79]. Among all of these techniques, coating the membrane surface with a hydrophobic layer is an efficient method of fabricating a composite membrane due to the simplicity of the procedure, low cost, and large volume of manufacturing. For example, Pan et al. [80] have successfully fabricated a composite membrane by using hydrophilic PVDF membrane as the supporting membrane. In this work, the PFPE membrane was coated on the supporting membrane by the dipcoating method. Based on the characterisation of the membrane, it has been shown that a coating layer has been applied to a substrate membrane and effectively cured without altering the original porosity structure or blocking the pores [81]. More importantly, the anti-wetting 
characteristics were significantly improved due to the addition of the coating layer. Micrometer or nanoscale fibers can be created via electrospinning. This promising and flexible technique uses a strong electric field to spin a polymer or biopolymer liquid solution into fibers of micrometer or nanometer size. Some researchers have used electrospun fibrous membranes in the MD process, and they have found that they have excellent performance on permeate flux and salt rejection [76, 77]. The excellent performance of the electrospun fibrous membrane is due to its high hydrophobicity, high porosity, low thickness, and interconnected open structure [84]. Li et al. [85] have fabricated a nanofibrous composite membrane by electrospinning method. This research employed two types of spacers and two non-woven fabrics as supports in the electrospinning fabrication process. Layers of PVDF nanofibers were linked openly in three dimensions, resulting in a rough surface on the composite membranes. The membrane surface developed a multilayer re-entrant structure due to the overlapping nanofibers and the presence of beads-on-string, and all contact angles of the electrospun membranes were over $140^{\circ}$. The electrospun composite membranes were evaluated by DCMD utilising a $3.5 \% \mathrm{NaCl}$ solution as feed, and the permeate flow reached a maximum of $49.3 \mathrm{~kg} / \mathrm{m}^{2} / \mathrm{hr}$ for the highest permeate flux. The long-term and repetitive operation of MD desalination revealed that the manufactured membrane exhibited excellent scaling and wetting resistance and was easy to clean. Therefore, it is considered that the electrospun fibrous $\mathrm{PVDF} / \mathrm{spacer}$ composite membrane has a great deal of promise for use in the medical device manufacturing process. The electrospinning method has been utilised by Li et al. [86] to fabricate a triple-layer membrane with outstanding anti-wetting performance. The membrane are consisted of hydrophobic PTFE-PVDF layer, PET support layer, and a chitosanpolyethylene oxide (CS-PEO) hydrophilic layer. Table 3 summarises the fabrication techniques for composite membrane.

Table 3 Summary of fabrication techniques used for composite membrane

\begin{tabular}{lllll}
\hline Polymer & Fabrication & $\begin{array}{l}\text { Water contact angle } \\
\left(^{\circ}\right)\end{array}$ & $\begin{array}{l}\text { Application } \\
\text { MD } \\
\text { configuration }\end{array}$ & and \\
\hline PVDF & Dip-coating & - & MD/VMD & {$[74]$} \\
PVDF & Electrospun & $>140^{\circ}$ & MD/DCMD & {$[79]$} \\
PVDF-PTFE & Electrospinning & 144 & MD/DCMD & {$[80]$} \\
\hline
\end{tabular}

\subsection{MODIFICATIONS ON MEMBRANE STRUCTURES}

A myriad of researches has been studied and concentrated on the membrane's surface modification to enhance the membrane properties, especially on physicochemical and thermal properties of the membranes. The surface modification has conventionally been accomplished by inserting desired functional group into the surface that may then be used to modify the membrane surface characteristics, particularly in wettability, surface roughness, and water contact angle [87]. Membranes with specific wettability characteristics have been proven to be the most effective for improving fouling and 
wetting resistance $[12,39,40]$ when compared to other membranes. With inspiration from nature, the special wettability on MD membranes has been achieved by adjusting surface roughness [88, 89], and chemical compositions via surface engineering [90].

Phase separation is shown to be a cost-effective and easy method of increasing surface roughness without using low surface energy modifiers to improve the hydrophobicity of the membrane. Rabiei et al. [91] have successfully enhanced the membrane surface's hydrophobicity through the phase separation of the PC solution on the PVDF membrane. Figure 3 present the SEM images of the membranes coated with different concentrations of the PC solution. Based on this figure, increasing the concentration of $\mathrm{PC}$ solutions has gradually covered the membrane surface with polycarbonate deposits, resulting in the hierarchical roughness on the surface of the pristine membrane. In addition, the coated membrane showed an increase in the water contact angle from $82^{\circ}$ to $130^{\circ}$ with the highest concentration of PC solution. Thus, this study shows that manipulating the surface roughness through the phase separation method has successfully improved the hydrophobicity of the membrane.

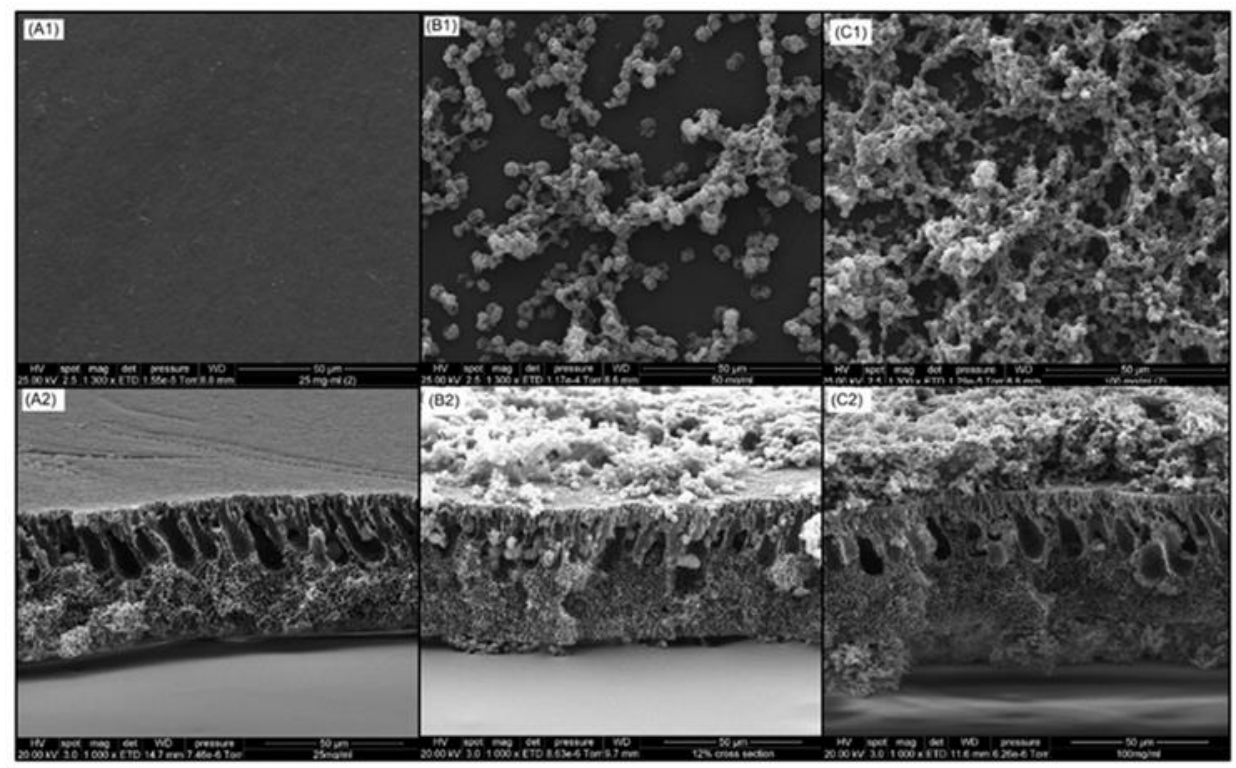

Figure 3 The SEM images of the surface and cross-section of the membranes coated with (A), $25 \mathrm{mg} / \mathrm{mL}$; (B), $50 \mathrm{mg} / \mathrm{mL}$; and (C), $100 \mathrm{mg} / \mathrm{mL}$ PC solution [85]

Nanoparticles and nanofibers are currently being used to modify MD membranes due to advancements in nanotechnological research. Nanoparticles have been included to improve the superhydrophobicity of the commercial membrane by enhancing the surface roughness and generating a multilayer structure on the membrane surface [35, 36]. Recent studies have demonstrated the modification of membranes by applying metallic nanoparticles. For example, Deka et al. [92] have successfully developed a modified PVDF-HFP membrane with zinc oxide, $\mathrm{ZnO}$ nanoparticles to improve the hydrophobic character of the membrane. In the presence of welldispersed fluorinated $\mathrm{ZnO} \mathrm{NPs}$, hierarchical micro/nanoscale spherical structures were produced on the 
micro/nanoscale (average diameter of $1.0 \mathrm{~mm}$ ) morphology of the re-entrant membrane. Furthermore, the nanoparticles' incorporation has formed the rough surface, which develops the air pocket on the membrane [93], allowing improper contact between water and the membrane surface. Due to the impact of combination re-entrant structures and the air pockets, the membrane attained superhydrophobicity while also exhibiting omniphobic characteristics.

Another study by Razmjao et al. [94] has utilised titanium dioxide, $\mathrm{TiO}_{2}$, to modify the PVDF membrane. The $\mathrm{TiO}_{2}$ has been coated on the PVDF membrane by a dip-coating method. Due to its simplicity and low overall cost of production [95], dip coating is a widely used coating technology compared to other alternative coating techniques such as spin coating, spray coating, or plasma treatments [96]. $1 \mathrm{H}$, $1 \mathrm{H}, \quad 2 \mathrm{H}, \quad 2 \mathrm{H}$-perfluoro-dodecyl trichlorosilane (FTCS) was employed to fluorinate the coated PVDF membrane. In this study, it has been observed that the modified FTCS$\mathrm{TiO}_{2}-\mathrm{PVDF}$ membrane is extremely hydrophobic due to the increase in water contact angle from the commercial PVDF membrane $\left(125^{\circ} \pm\right.$ $\left.1^{\circ}\right)$ to $\mathrm{FTCS}-\mathrm{TiO}_{2}-\mathrm{PVDF}$ membrane $\left(163^{\circ} \pm 3^{\circ}\right)$. The increase in water contact angle has resulted from the substantial reduction in surface free energy and increase in roughness reported for FTCS-PVDF membranes. Recent studies by Zhang et al. [97] presented the application of polydopamine (PDA) and poly(MPCco-2-aminoethyl methacrylate hydrochloride) (MPC-co-AEMA) for the modification of PVDF hollow fibre membrane. The co-deposition of PDA/MPC-co-easy AEMA's on the membrane's outer surface dramatically changed the surface's chemical and physical properties. The modification has been successfully shown to improve the membrane resistance towards fouling and scaling issues during the MD process. In this work, with increasing co-deposition time, the porosity, pore size, and roughness of the membrane surface decreased while the hydrophilicity of the membrane increased. The bulk structure of the membrane remained essentially the same throughout the experiment. The effect of the PTFE additive on the modification of the PVDF-CTFE layer has been investigated by Ray et al. [98]. The PVDF-CTFE layer was changed by using PTFE mixing and PFS polymerisation to improve its performance and hydrophobicity. It has been proven that adding $10 \mathrm{wt} \%$ PTFE to the PVDF-CTFE layer changed the pore structure. The hydrophobicity was increased by changing the PFS, as demonstrated by the contact angle and LEP values of the modified PFS. When PTFE and PFS are blended, it is possible to achieve a high flux by modifying the pore structure. The hydrophobicity of the membrane is increased by polymerisation of PFS, which allows the modified membrane to be employed for preventing wetting phenomena during the VMD process.

\subsection{CHARACTERISATION AND PERFORMANCE OF MEMBRANE DISTILLATION}

In applying the separation process by membrane distillation, membrane morphology is a crucial component as it is closely related to membrane performances. Therefore, the characterisation of such membranes is necessary to better understand their performance and build membranes designed explicitly for the MD process [99]. Many approaches are available for determining the morphological 
characteristics of interest, starting with microscopy, such as scanning electron microscopy (SEM), atomic force microscopy (AFM), and water contact angle.

SEM is one of the most critical techniques for membrane characterisation since it provides information on the morphology and topography of the membrane. Furthermore, it also can be used to determine the pore size of a porous membrane [100]. In recent studies, $M$. Tian et al. [101] have utilised SEM to investigate the morphology structure of the isotropic PVDF membrane prepared by one step-fabrication. The porous PVDF membranes used in this study were created utilising a simple bottom-up technique that relied on water as a coagulation bath. The isotropic skinless PVDF structure was fabricated in the water bath by coating a non-woven substrate with the developing film and immersing it in the bath. Figures 4 and 5 illustrated the SEM images of the membrane morphologies from the cross-section and top surface of the membranes, respectively. The figures revealed that the membrane surface morphology via the bottom-up method differs from the typical phase inversion method. The membrane forms a rough top surface and sponge-like granular membranes consisting of spherulites.

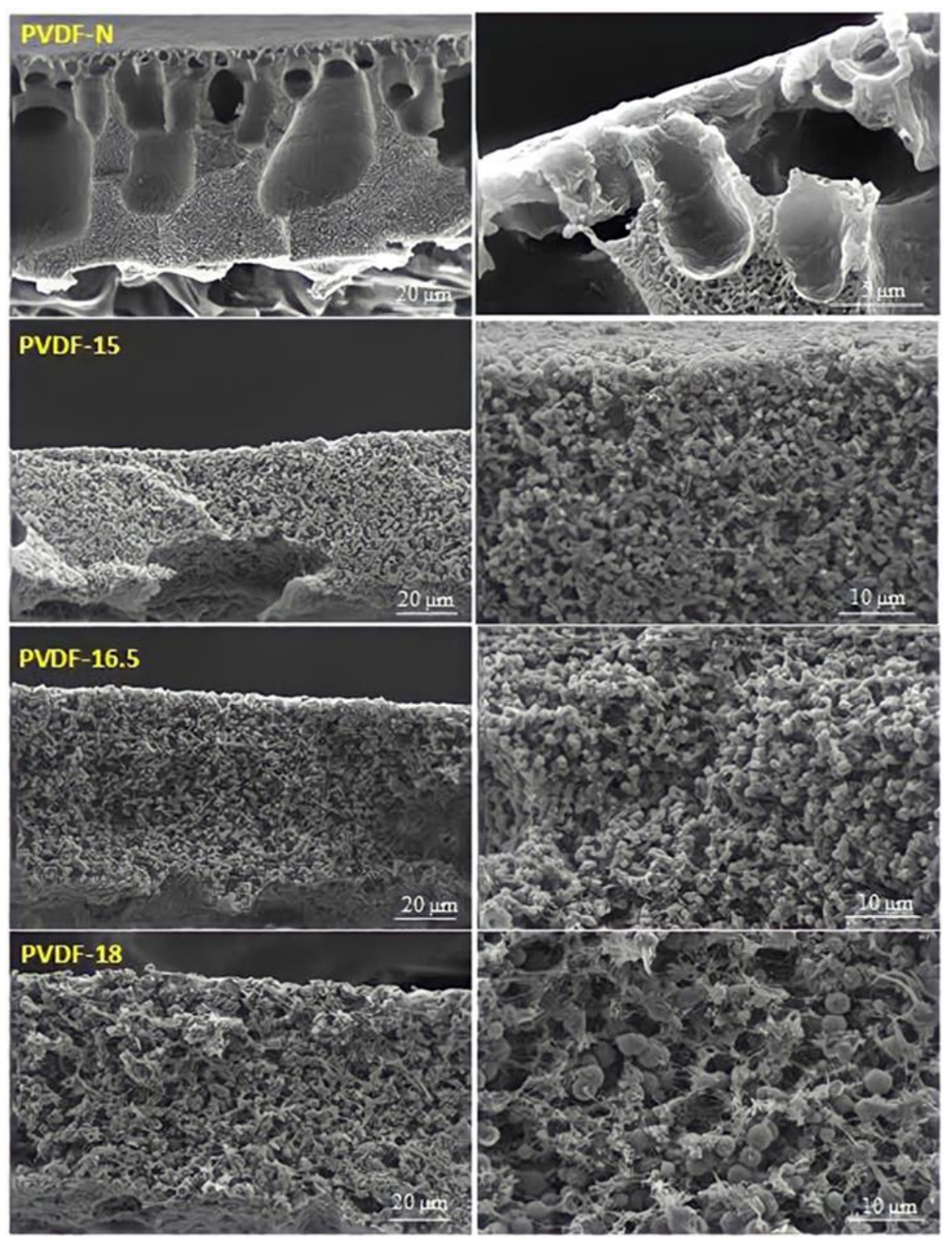

Figure 4 The SEM image of the cross-section of the normal casting and bottom-up casting membrane [95] 


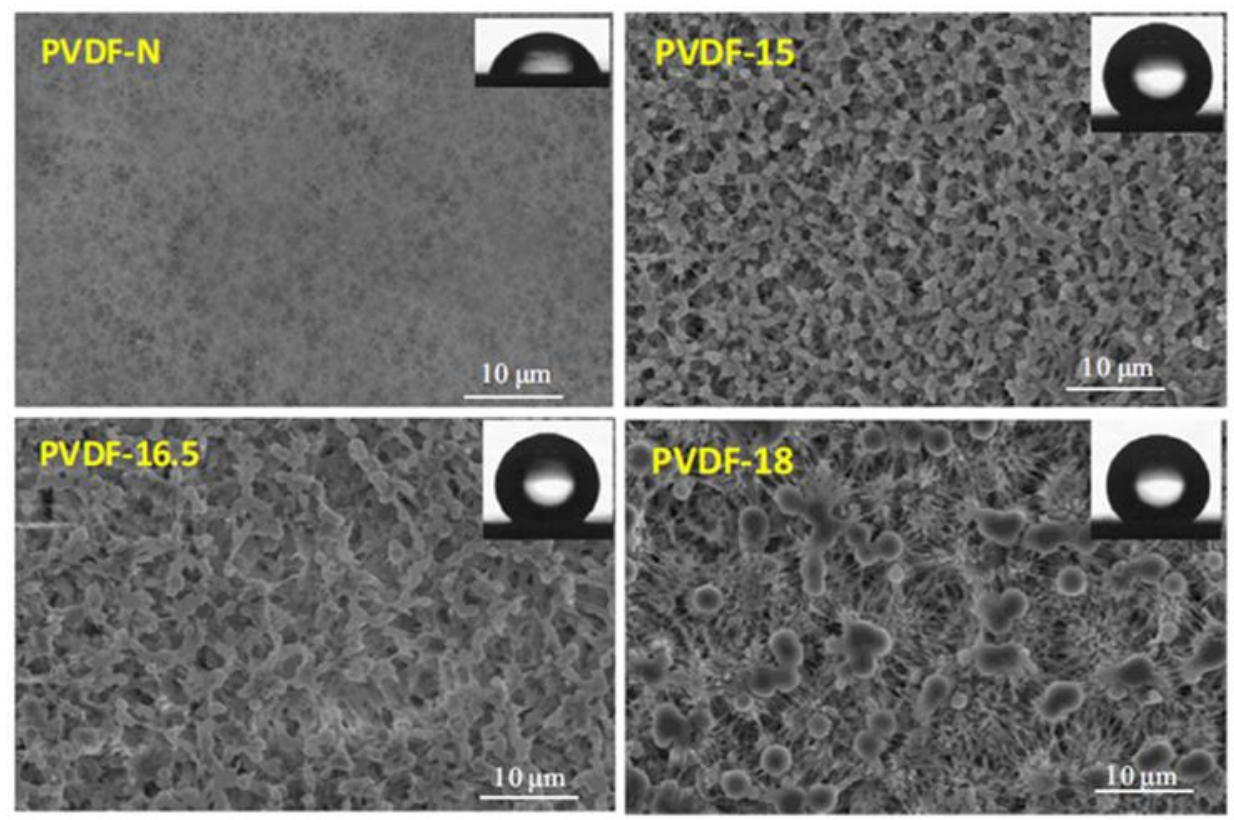

Figure 5 The SEM images of the top surface of the normal casting and bottom-up membranes [95]

In comparison to other microscopic technologies like SEM and AFM provides more detailed information on surface morphology and a threedimensional (3D) perspective of membrane topography without the need for sample preparation [99]. Figure 6 depicts the AFM images of the PVDF membrane. The surface roughness of the PVDF-N membrane increases dramatically from $0.0718 \mathrm{~m}$ to $0.375 \mathrm{~m}$ when the bottom-up membrane is used with the same concentration of the PVDF dope

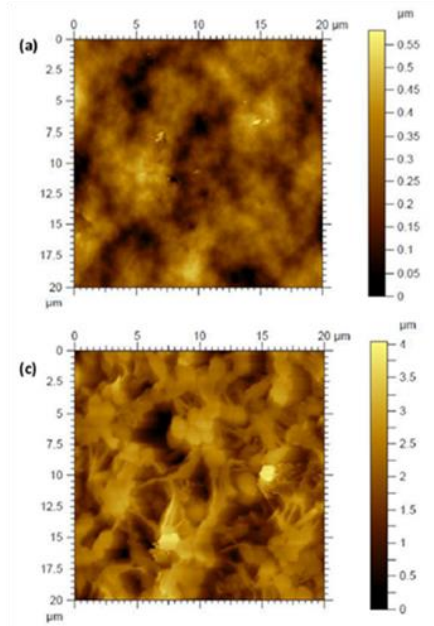

solution as the PVDF-N membrane due to the formation of a particulate surface. The effective production of highly hydrophobic PVDF membranes employing a water bath for phase inversion is confirmed by a rapid increase in water contact angles from conventional casting membranes $\left(71.7^{\circ}\right)$ to the bottom-up membrane $\left(144^{\circ}\right)$. This simple, low-impact technique opens the door to massproducing high-performance MD membranes on a massive scale.

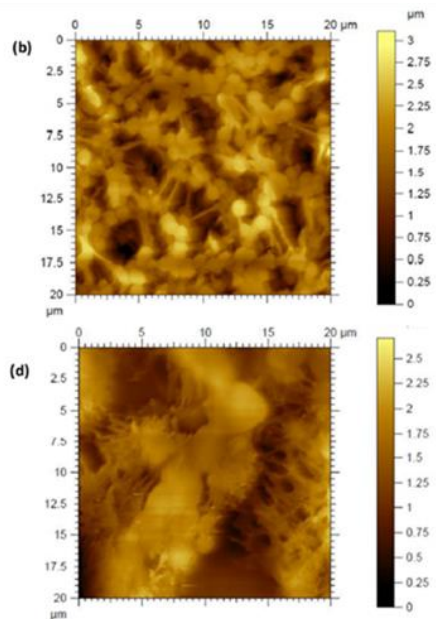

Figure 6 The AFM images of the normal casting and bottom-up membranes. (a) PVDF-N, (b) PVDF-15, (c) PVDF-16.5, and (d) PVDF-18 [95] 
The characterisation by AFM technique was conducted by Shirazi et al. [99] to characterise three hydrophobic membranes (PTFE, PP, and PVDF), which are often employed in various MD applications. Their pore size and pore size distribution, surface roughness, and hydrophobicity were measured to characterise the membranes. The fabrication technique can directly impact the pore size and pore size distribution and the surface topography of the material. The membranes with a size of $0.22 \mu \mathrm{m}$ are generally explored as the optimum choice for different MD applications [102]. The SEM pictures of the membranes examined in this study observed a completely distinct surface topography and morphology and a non-circular pore structure in each of the membranes studied. With the help of the AFM technique, it was possible to determine the pore size and pore size distribution of these membranes, as indicated in Figure 7. From the AFM observation, the pore size of PVDF, PP, and PTFE membranes have values of $0.311 \mu \mathrm{m}, 0.282 \mu \mathrm{m}$, and $0.278 \mu \mathrm{m}$, respectively.

Both the intrinsic hydrophobicity of the polymer and the surface roughness of the polymer are essential factors in determining hydrophobicity. Surface roughness can be used to indicate surface irregularities that occur during the production process of the material. Roughness statistics derived from experimental analysis such as AFM provide quantitative information about the shape of membranes [97, 98]. In general, the attainment of multi-scale surface structures increases the hydrophobicity of the membrane surfaces [105, 106]. This study investigated the inherent hydrophobicity of polymers such as PTFE, polypropylene, and PVDF by measuring the surface contact angle of their flat sheets. For PTFE, PP, and
PVDF sheets, the obtained values were $120.7^{\circ}, 103.2^{\circ}$, and $90.5^{\circ}$, respectively, with PTFE being the highest and PP being the lowest. AFM may also be used to measure the roughness of a practical surface directly. AFM analysis offers about 15 distinct roughness characteristics, which may be utilised for topographical investigations and surface energy measurements on various materials.

\subsection{CONCLUSION AND FUTURE PERSPECTIVES}

In this review, the membrane's fabrication, modification, characterisation, and morphological structure have all been addressed. It has been shown that the morphological characteristics of the membrane will affect the performance of the MD separation process. The surface roughness, wettability, and water contact angle are several characteristics that describe the morphological structure of a membrane used in membrane distillation that has been analysed in this review. Through the employment of various fabrication methods, including phase inversion, sintering, extrusion, and electrospinning accompanied with the modification of the surface, membranes with superhydrophilicity, improved MD performance, antiwetting, and anti-fouling features have been developed and tested. In addition, a better in-depth understanding of the membrane materials best suited for the MD process can be observed through various characterisation techniques such as SEM, AFM, and water contact angle measurement. Tremendous efforts had been made to develop a suitable membrane for an effective membrane distillation process. However, despite the vast progress that has been in MD membrane research 
and technology, there are still some significant obstacles that need to be addressed immediately. For example, there is a lack of membranes with high wetting resistance and permeation flux for treating wastewater containing high salinity and high concentration of low surface tension compounds such as surfactants or oil. To overcome these difficulties, an immense number of works is vital to enhance the fabrication of membranes with better characteristics and properties for efficient membrane distillation performances.
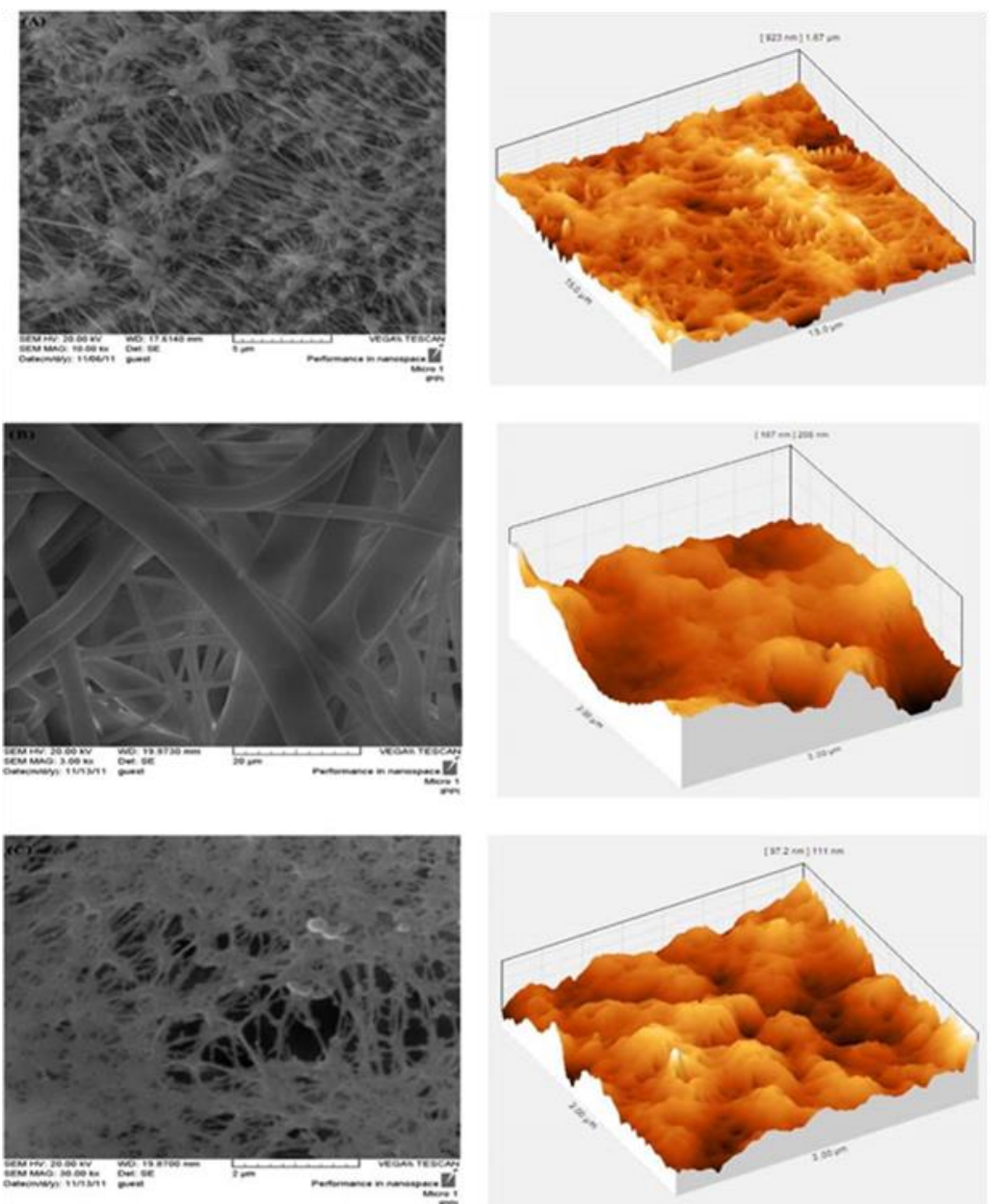

Figure 5 The AFM (right) and SEM (left) images of (A) PTFE, (B) PP, and (C) PVDF membranes with $0.2 \mu \mathrm{m}$ reported pore size[93]

\section{ACKNOWLEDGMENT}

The authors were gratefully acknowledged by the Malaysia Ministry of Higher Education (MOHE) for the FRGS research funding (600IRMI/FRGS 5/3 (441/2019)).

\section{REFERENCES}

[1] K. Rasool, R. P. Pandey, P. A.
Rasheed, S. Buczek, Y. Gogotsi, K. A. Mahmoud. 2019. Water Treatment and Environmental Remediation Applications of Two-dimensional Metal Carbides (MXenes). Materials Today. 30: 80-102.

Doi:10.1016/j.mattod.2019.05.01 7.

[2] S. M. F. Islam, Z. Karim. 2019. World's Demand for Food and Water: The Consequences of 
Climate Change. Desalination Challenges and Opportunities. Doi:10.5772/INTECHOPEN.859 19.

[3] A. Boretti, L. Rosa. 2019. Reassessing the Projections of the World Water Development Report. Npj Clean Water. 2:1. 2 1-6. Doi:10.1038/s41545-0190039-9.

[4] B. S. Lalia, V. Kochkodan, R. Hashaikeh, N. Hilal. 2013. A Review on Membrane Fabrication: Structure, Properties and Performance Relationship. Desalination. 326: 77-95. Doi:10.1016/J.DESAL.2013.06.0 16.

[5] E. O. Ezugbe, S. Rathilal. 2020. Membrane Technologies in Wastewater Treatment: A Review. Membranes. 10. Doi: 10.3390/membranes 1005008 9.

[6] L. Le Ngoc, P. N. Suzana. 2016. Materials and Membrane Technologies for Water and Energy Sustainability. Sustainable Materials and Technologies. 7: 1-28.

[7] S. Roy, S. Ragunath. 2018. Emerging Membrane Technologies for Water and Energy Sustainability: Future Prospects, Constraints and Challenges. Energies. 11: 2997. Doi:10.3390/EN11112997.

[8] M. H. Abd Aziz, M. H. Dzarfan Othman, N. H. Alias, T. Nakayama, Y. Shingaya, N. A. Hashim, T. A. Kurniawan, T. Matsuura, M. A. Rahman, J. Jaafar. 2020. Enhanced Omniphobicity of Mullite Hollow Fiber Membrane with Organosilane-functionalized

$\mathrm{TiO} 2$ Micro-flowers and Nanorods Layer Deposition for Desalination using Direct Contact Membrane Distillation.
Journal of Membrane Science. 607:

118137.

Doi:10.1016/j.memsci.2020.1181 37.

[9] Z. S. Tai, M. H. Abd Aziz, M. H. D. Othman, M. I. H. Mohamed Dzahir, N. A. Hashim, K. N. Koo, S. K. Hubadillah, A. F. Ismail, M. A. Rahman, J. Jaafar. 2019. Ceramic Membrane Distillation for Desalination. Separation \& Purification Reviews. $\quad$ 001-40. Doi:10.1080/15422119.2019.161 0975.

[10] M. Qasim, I. U. Samad, N. A. Darwish, N. Hilal. 2021. Comprehensive Review of Membrane Design and Synthesis for Membrane Distillation. Desalination. 518: 115168. doi:10.1016/J.DESAL.2021.1151 68.

[11] M. Khayet. 2011. Membranes and Theoretical Modeling of Membrane Distillation: A Review. Advances in Colloid and Interface Science. 164: 56-88. Doi:10.1016/J.CIS.2010.09.005.

[12] S. K. Hubadillah, Z. S. Tai, M. H. D. Othman, Z. Harun, M. R. Jamalludin, M. A. Rahman, J. Jaafar, A. F. Ismail. 2019. Hydrophobic Ceramic Membrane for Membrane Distillation: A Mini Review on Preparation. Characterization, and Applications, Separation and Purification Technology. 217: 71-84.

Doi:10.1016/j.seppur.2019.02.01 4.

[13] P. Wang, T. S. Chung. 2015. Recent Advances in Membrane Distillation Processes: Membrane Development, Configuration Design and Application Exploring. Journal of Membrane Science. 474: 3956. 
Doi:10.1016/j.memsci.2014.09.0 16.

[14] Z. Wang, S. Lin. 2017. Membrane Fouling and Wetting in Membrane Distillation and Their Mitigation by Novel Membranes with Special Wettability. Water Research. 112: $\quad 38-47$. Doi:10.1016/j.watres.2017.01.02 2.

[15] Y. Dong, X. Dai, L. Zhao, L. Gao, Z. Xie, J. Zhang. 2021. Review of Transport Phenomena and Popular Modelling Approaches in Membrane Distillation. Membranes. 11: 127.

Doi:10.3390/membranes1102012 2.

[16] L. M. Camacho, L. Dumée, J. Zhang, J. de Li, M. Duke, J. Gomez, S. Gray. 2013. Advances in Membrane Distillation for Water Desalination and Purification Applications. Water. (Switzerland).

Doi:10.3390/w5010094.

[17] C. J. Davey, P. Liu, F. Kamranvand, L. Williams, Y. Jiang, A. Parker, S. Tyrrel, E. J. McAdam. 2021. Membrane Distillation for Concentrated Blackwater: Influence of Configuration (Air Gap, Direct Contact, Vacuum) on Selectivity and Water Productivity. Separation and Purification Technology. 263: 118390. Doi:10.1016/J.SEPPUR.2021.11 8390.

[18] D. Winter, J. Koschikowski, M. Wieghaus. 2011. Desalination using Membrane Distillation: Experimental Studies on Full Scale Spiral Wound Modules, Journal of Membrane Science. 375: 104-112. Doi:10.1016/J.MEMSCI.2011.03 .030 .
[19] C. Dotremont, B. Kregersman, R. Sih, K. C. Lai, K. Koh, H. Seah. 2010. Seawater Desalination With Memstill Technology - A Sustainable Solution for the Industry. Water Practice and Technology. 5. Doi:10.2166/WPT.2010.026.

[20] J. H. Hanemaaijer. 2004. Memstill@ - Low Cost Membrane Distillation Technology for Seawater Desalination. Desalination. 168: 355.

Doi:10.1016/J.DESAL.2004.07.0 19.

[21] S. Kalla, S. Upadhyaya, K. Singh. 2019. Principles and Advancements of Air Gap Membrane Distillation. Reviews in Chemical Engineering. 35: 817-859. Doi:10.1515/REVCE2017-0112.

[22] P. Wang, T. S. Chung. 2012. Design and Fabrication of LotusRoot-Like Multi-Bore Hollow Fiber Membrane for Direct Contact Membrane Distillation. Journal of Membrane Science. 421-422, 361-374. Doi:10.1016/J.MEMSCI.2012.08 .003 .

[23] L. Francis, H. Maab, A. AlSaadi, S. Nunes, N. Ghaffour, G. L. Amy. 2013. Fabrication of Electrospun Nanofibrous Membranes for Membrane Distillation Application. New Pub: Balaban. 51: 1337-1343. Doi:10.1080/19443994.2012.700 037.

[24] H. Yu, X. Yang, R. Wang, A. G. Fane. 2011. Numerical simulation of Heat and Mass Transfer in Direct Membrane Distillation in a Hollow Fiber Module with Laminar Flow, Journal of Membrane Science. 384:

107-16.

Doi:10.1016/J.MEMSCI.2011.09 
.011 .

[25] P. Biniaz, N. T. Ardekani, M. A. Makarem, M. R. Rahimpour. 2019. Water and Wastewater Treatment Systems by Novel Integrated Membrane Distillation (MD). Chem Engineering. 3: 8. Doi:10.3390/CHEMENGINEER ING3010008.

[26] A. Alkhudhiri, N. Darwish, N. Hilal. 2012. Membrane Distillation: A Comprehensive Review. Desalination. Doi:10.1016/j.desal.2011.08.027.

[27] M. R. S. Kebria, A. Rahimpour. 2020. Membrane Distillation: Basics, Advances, and Applications. Advances in Membrane Technologies. Doi:10.5772/INTECHOPEN.869 52.

[28] C. K. Chiam, R. Sarbatly. 2013. Vacuum Membrane Distillation Processes for Aqueous Solution Treatment-A Review. Chemical Engineering and Processing Process Intensification. 74: 2754.

Doi:10.1016/J.CEP.2013.10.002.

[29] I. A. Said, T. Chomiak, J. Floyd, Q. Li. 2020. Sweeping Gas Membrane Distillation (SGMD) for Wastewater Treatment, Concentration, and Desalination: A Comprehensive Review. Chemical Engineering and Processing - Process Intensification. 153: 107960. Doi:10.1016/J.CEP.2020.107960

[30] M. Tomaszewska. 2014. Sweep Gas Membrane Distillation (SGMD). Encyclopedia of Membranes. 1-3. Doi:10.1007/978-3-642-408724_769-2.

[31] M. Afsari, H. K. Shon, L. D. Tijing. 2021. Janus Membranes for Membrane Distillation : Recent Advances and Challenges. Advan. 289: 102362.
Doi:10.1016/j.cis.2021.102362.

[32] F. Tibi, A. Charfi, J. Cho, J. Kim. 2020. Fabrication of Polymeric Membranes for Membrane Distillation Process and Application for Wastewater Treatment: Critical Review. Process Safety and Environmental Protection. 141: 190-201.

Doi:10.1016/J.PSEP.2020.05.02 6.

[33] N. Nady, N. Salem, S. H. Kandil, D. J. Yoo. 2021. Preparation and Characterization of a Novel Poly(vinylidene fluoride-cohexafluoropropylene)/Poly(ether sulfone) Blend Membrane Fabricated Using an Innovative Method of Mixing Electrospinning and Phase Inversion. Polymers. 13(5). Doi:10.3390/polym13050790.

[34] C. Li, J. Zhang, J. Han, B. Yao. 2021. A Numerical Solution to the Effects of Surface Roughness on Water-coal Contact Angle. Scientific Reports. 11(1): 1-12. Doi:10.1038/s41598-020-807299.

[35] V. Belessiotis, S. Kalogirou, E. Delyannis. 2016. Membrane Distillation. Thermal Solar Desalination. 191-251. Doi:10.1016/B978-0-12-8096567.00004-0.

[36] V. M.-W. Yim, A. S.-W. Lo, B. J. Deka, J. Guo, J. A. Kharraz, I. T. Horváth, A. K. An. 2020. Molecular Engineering Lowsurface Energy Membranes by Grafting Perfluoro-Tert-Butoxy Chains Containing Fluorous Silica Aerogels. Green Chemistry. 22: 3283-3295. Doi:10.1039/D0GC00593B.

[37] W. Jia, J. A. Kharraz, J. Sun, A. K. An. 2021. Hierarchical Janus Membrane via a Sequential Electrospray Coating Method 
with Wetting and Fouling

Resistance for Membrane

Distillation. Desalination. 520:

115313.

Doi:10.1016/J.DESAL.2021.115

313.

[38] M. Yao, L. D. Tijing, G. Naidu, S. H. Kim, H. Matsuyama, A. G. Fane, H. K. Shon. 2020. A Review of Membrane Wettability for the Treatment of Saline Water Deploying Membrane Distillation. Desalination. 479: 114312. Doi:10.1016/j.desal.2020.114312

[39] A. K. An, E. J. Lee, J. Guo, S. Jeong, J. G. Lee, N. Ghaffour. 2017. Enhanced Vapor Transport in Membrane Distillation via Functionalized Carbon Nanotubes Anchored into Electrospun Nanofibres. Scientific Reports. 7: 1-11. Doi:10.1038/srep41562.

[40] X. Li, X. Yu, C. Cheng, L. Deng, M. Wang, X. Wang. 2015. Electrospun Superhydrophobic Organic/Inorganic Composite Nanofibrous Membranes for Membrane Distillation. ACS Applied Materials and Interfaces. 7: 21919-. Doi:10.1021/ACSAMI.5B06509.

[41] T. Horseman, Y. Yin, K. S. Christie, Z. Wang, T. Tong, S. Lin. 2021. Wetting, Scaling, and Fouling in Membrane Distillation: State-of-the-Art Insights on Fundamental Mechanisms and Mitigation Strategies. ACS ES\&T Engineering. 1: 117-140. Doi:10.1021/acsestengg.0c00025

[42] X. Lu, Y. Peng, H. Qiu, X. Liu, L. Ge. 2017. Anti-fouling Membranes by Manipulating Surface Wettability and Their Anti-fouling Mechanism. Desalination. 413: 127-135. Doi:10.1016/J.DESAL.2017.02.0
22.

[43] V. Karanikola, A. F. Corral, H. Jiang, A. E. Sáez, W. P. Ela, R. G. Arnold. 2017. Effects of Membrane Structure and Operational Variables on Membrane Distillation Performance. Journal of Membrane Science. 524: 87-96. Doi:10.1016/J.MEMSCI.2016.11 .038 .

[44] H. Chamani, T. Matsuura, D. Rana, C. Q. Lan. 2019. Modeling of Pore Wetting in Vacuum Membrane Distillation. Journal of Membrane Science. 572: 332342.

Doi:10.1016/J.MEMSCI.2018.11 .018 .

[45] J. G. Lee, E. J. Lee, S. Jeong, J. Guo, A. K. An, H. Guo, J. Kim, T. O. Leiknes, N. Ghaffour. 2017. Theoretical Modeling and Experimental Validation of Transport and Separation Properties of Carbon Nanotube Electrospun Membrane Distillation. Journal of Membrane Science. 526: 395408.

Doi:10.1016/J.MEMSCI.2016.12 .045 .

[46] L. García-Fernández, M. Khayet, M. C. García-Payo. 2015. Membranes used in Membrane Distillation: Preparation and Characterization, Pervaporation. Vapour Permeation and Membrane Distillation: Principles and Applications. 318-359. Doi:10.1016/B978-178242-246-4.00011-8.

[47] L. Eykens, K. De Sitter, C. Dotremont, L. Pinoy, B. Van Der Bruggen. 2016. How to Optimize the Membrane Properties for Membrane Distillation: A Review. Industrial and Engineering Chemistry Research. 55: 9333-9343. 
Doi:10.1021/acs.iecr.6b02226.

[48] N. H. Alias, J. Jaafar, S. Samitsu, T. Matsuura, A. F. Ismail, S. Huda, N. Yusof, F. Aziz. 2019. Photocatalytic Nanofiber-coated Alumina Hollow Fiber Membranes for Highly Efficient Oilfield Produced Water Treatment. Chemical Engineering Journal. 360: 14371446.

Doi:10.1016/j.cej.2018.10.217.

[49] S. S. Ray, S.-S. Chen, C. Thanh, N. Dan, H.-T. Hsu, H.-M. Chang, N. C. Nguyen, H.-T. Nguyen. 2018. Casting of a Superhydrophobic Membrane Composed of Polysulfone/Cera Flava for Improved Desalination using a Membrane Distillation Process.

Doi:10.1039/c7ra12474k.

[50] N. H. Alias, J. Jaafar, S. Samitsu, A. F. Ismail, M. H. D. Othman, M. A. Rahman, N. H. Othman, N. Yusof, F. Aziz, T. A. T. Mohd. 2020. Efficient Removal of Partially Hydrolysed Polyacrylamide in PolymerFlooding Produced Water Using Photocatalytic Graphitic Carbon Nitride Nanofibres. Arabian Journal of Chemistry. 13: 43414349.

[51] N. H. Alias, J. Jaafar, S. Samitsu, N. Yusof, M. H. D. Othman, M. A. Rahman, A. F. Ismail, F. Aziz, W. N. W. Salleh, N. H. Othman. 2018. Photocatalytic Degradation of Oilfield Produced Water using Graphitic Carbon Nitride Embedded in Electrospun Polyacrylonitrile Nanofibers. Chemosphere. 204: 79-86. Doi:10.1016/j.chemosphere.2018 .04.033.

[52] N. Fatin, D. Junaidi, H. Othman. 2020. Fabrication and Characterization of Graphene Oxide - Polyethersulfone (GO -
PES) Composite Flat Sheet and Hollow Fiber Membranes for Oil - Water Separation. Journal of Chemical Technology Biotechnology. 95: 1308-1320. Doi:10.1002/jctb.6366.

[53] U. N. Rusli, N. H. Alias, M. Z. Shahruddin, N. H. Othman. 2016. Photocatalytic Degradation of Oil Using Polyvinylidene Fluoride/Titanium Dioxide Composite Membrane for Oily Wastewater Treatment. MATEC Web of Conferences, 2016. 1-5. Doi:10.1051/matecconf/2016690 5003.

[54] N. H. Alias, J. Jaafar, S. Samitsu, N. Yusof, M. Hafiz, D. Othman, M. A. Rahman, A. Fauzi Ismail, F. Aziz, W. Norharyati, W. Salleh, N. H. Othman. 2018. Photocatalytic Degradation of Oilfield Produced Water Using Graphitic Carbon Nitride Embedded in Electrospun Polyacrylonitrile Nanofibers. Chemosphere. 204: 79-86. Doi:10.1016/j.chemosphere.2018 .04.033.

[55] N. H. Alias, J. Jaafar, S. Samitsu, A. F. Ismail, M. H. D. Othman, M. A. Rahman, N. H. Othman, N. Yusof, F. Aziz, T. A. T. Mohd. 2019. Efficient Removal of Partially Hydrolysed Polyacrylamide in PolymerFlooding Produced Water using Photocatalytic Graphitic Carbon Nitride Nanofibres. Arabian Journal of Chemistry. Doi:10.1016/j.arabjc.2019.08.00 4.

[56] N. H. Alias, J. Jaafar, S. Samitsu, A. F. Ismail, N. A. M. Nor, N. Yusof, F. Aziz. 2020. Mechanistic Insight of the Formation of Visible-light Responsive Nanosheet Graphitic Carbon Nitride Embedded Polyacrylonitrile Nanofibres for 
Wastewater Treatment. Journal of Water Process Engineering. 33: 101015. Doi:10.1016/j.jwpe.2019.101015

[57] X. Tan, D. Rodrigue. 2019. A Review on Porous Polymeric Membrane Preparation. Part I: Production Techniques with Polysulfone and Poly (Vinylidene Fluoride). 11(7). Doi:10.3390/polym11071160.

[58] S. Ashtiani, M. Khoshnamvand, P. Č́́hal, M. Dendisová, A. Randová, D. Bouša, A. Shaliutina-Kolešová, Z. Sofer, K. Friess. 2020. Fabrication of a PVDF Membrane with Tailored Morphology and Properties: Via Exploring and Computing Its Ternary Phase Diagram for Wastewater Treatment and Gas Separation Applications. RSC Advances. 10: 40373-40383. Doi:10.1039/d0ra07592b.

[59] S. Nejati, C. Boo, C. O. Osuji, M. Elimelech. 2015. Engineering Flat Sheet Microporous PVDF Films for Membrane Distillation. Journal of Membrane Science. 492: 355-363. Doi:10.1016/j.memsci.2015.05.0 33.

[60] S. Munirasu, F. Banat, A. A. Durrani, M. A. Haija. 2017. Intrinsically Superhydrophobic PVDF Membrane by Phase Inversion for Membrane Distillation. Desalination. 417: 77-86.

Doi:10.1016/J.DESAL.2017.05.0 19.

[61] R. Thomas, E. Guillen-Burrieza, H. A. Arafat. 2014. Pore Structure Control of PVDF Membranes using a 2-stage Coagulation Bath Phase Inversion Process for Application in Membrane Distillation (MD). Journal of Membrane Science. 452: 470-
480.

Doi:10.1016/J.MEMSCI.2013.11 .036 .

[62] S. Mohsen Samaei, S. GatoTrinidad, A. Altaee. 2018. The Application of Pressure-Driven Ceramic Membrane Technology for the Treatment of Industrial Wastewaters -A Review, Separation and Purification Technology. 200: 198-220. Doi:10.1016/j.seppur.2018.02.04 1.

[63] J. W. Wang, X. Z. Li, M. Fan, J. Q. Gu, L. Y. Hao, X. Xu, C. S. Chen, C. M. Wang, Y. Z. Hao, S. Agathopoulos. 2017. Porous $\beta$ Sialon Planar Membrane with a Robust Polymer-derived Hydrophobic Ceramic Surface, Journal of Membrane Science. 535:

Doi:10.1016/J.MEMSCI.2017.04 .028 .

[64] K. Bin Bandar, M. D. Alsubei, S. A. Aljlil, N. Bin Darwish, N. Hilal. 2021. Membrane Distillation Process Application Using a Novel Ceramic Membrane for Brackish Water Desalination. Desalination. 500: 114906.

Doi:10.1016/J.DESAL.2020.114 906.

[65] Y. Zhao, P. Li, R. Li, X. Li. 2019. Direct Filtration for the Treatment of the Coagulated Domestic Sewage using FlatSheet Ceramic Membranes. Chemosphere. 223: 383-390. Doi:10.1016/j.chemosphere.2019 .02 .055 .

[66] Y. Zhao, P. Li, R. Li, X. Li. 2020. Characterization and Mitigation of the Fouling of Flatsheet Ceramic Membranes for Direct Filtration of the Coagulated Domestic Wastewater. Journal of Hazardous Materials. 385: 
121557.

Doi:10.1016/j.jhazmat.2019.121 557.

[67] M. Haiqal, A. Aziz, M. Hafiz, D. Othman, N. Hashimah, T. Nakayama, Y. Shingaya, N. A. Hashim, T. Agustiono, T. Matsuura, M. A. Rahman, J. Jaafar. 2020. Enhanced Omniphobicity of Mullite Hollow Fiber Membrane with Organosilane-functionalized $\mathrm{TiO}$ 2 Micro-flowers and Nanorods Layer Deposition for Desalination using Direct Contact Membrane Distillation. Journal of Membrane Science. 607: 118137.

Doi:10.1016/j.memsci.2020.1181 37.

[68] N. H. Alias, J. Jaafar, S. Samitsu, T. Matsuura, A. F. Ismail, M. H. D. Othman, M. A. Rahman, N. H. Othman, N. Abdullah, S. H. Paiman, N. Yusof, F. Aziz. 2019. Photocatalytic Nanofiber-coated Alumina Hollow Fiber Membranes for Highly Efficient Oilfield Produced Water Treatment. Chemical Engineering Journal. 360. Doi:10.1016/j.cej.2018.10.217.

[69] A. Sailah, S. Nur, H. Alias, M. Zaman, S. Syed, S. Asghrar, S. Hassan. 2018. Sol-gel-derived Perovskite-based Sorbents for High-temperature Air Separation. Journal of Sol-Gel Science and Technology. Doi:10.1007/s10971-018-4865-x.

[70] Z. S. Tai, M. H. D. Othman, A. Mustafa, J. Ravi, K. C. Wong, K. N. Koo, S. K. Hubadillah, M. A. Azali, N. H. Alias, B. C. Ng, M. I. H. Mohamed Dzahir, A. F. Ismail, M. A. Rahman, J. Jaafar. 2021. Development of Hydrophobic polymethylhydrosiloxane/tetraet hylorthosilicate (PMHS/TEOS)
Hybrid Coating on Ceramic Membrane for Desalination via Membrane Distillation. Journal of Membrane Science. 637: 119609.

Doi:10.1016/j.memsci.2021.1196 09.

[71] Z. S. Tai, M. Hafiz Dzarfan Othman, A. Mustafa, M. I. H. Mohamed Dzahir, S. K. Hubadillah, K. N. Koo, M. A. Azali, N. H. Alias, B. Seng Ooi, T. A. Kurniawan, A. F. Ismail. 2021. Design and Characterization of Ceramic Hollow Fiber Membrane Derived from Waste Ash Using Phase Inversion-based

Extrusion/Sintering Technique for Water Filtration. Journal of Asian Ceramic Societies. 00: 118.

Doi:10.1080/21870764.2020.186 8080.

[72] M. R. Adam, M. H. D. Othman, S. H. Sheikh Abdul Kadir, M. H. Puteh, M. R. Jamalludin, N. A. H. Md Nordin, M. A. Ab Rani, A. Mustafa, M. A. Rahman, J. Jaafar. 2021. Fabrication, Performance Evaluation, and Optimisation of Adsorptive Ammonia Removal Using Hollow Fibre Ceramic Membrane: Response Surface Methodology Approach. Microporous and Mesoporous Materials. $\quad 316$ : 110932. Doi:10.1016/J.MICROMESO.20 21.110932.

[73] M. Lee, Z. Wu, K. Li. 2015. Advances in Ceramic Membranes for Water Treatment. Doi:10.1016/B978-1-78242-1214.00002-2.

[74] N. Abdullah, M. a. Rahman, M. H. D. Othman, A. F. Ismail, J. Jaafar, A. A. Aziz. 2016. Preparation and Characterization of Self-cleaning Alumina Hollow 
Fiber Membrane using the Phase Inversion and Sintering Technique. Ceramics International. 42: 12312-12322. Doi:10.1016/j.ceramint.2016.05. 003.

[75] S. Emani, R. Uppaluri, M. K. Purkait. 2014. Cross Flow Microfiltration of Oil-water Emulsions Using Kaolin based Low Cost Ceramic Membranes. Desalination. 341: 61-71. Doi:10.1016/J.DESAL.2014.02.0 30.

[76] M. R. Adam, T. Matsuura, M. H. D. Othman, M. H. Puteh, M. A. B. Pauzan, A. F. Ismail, A. Mustafa, M. A. Rahman, J. Jaafar, M. S. Abdullah. Feasibility Study of the Hybrid Adsorptive Hollow Fibre Ceramic Membrane (HFCM) Derived from Natural Zeolite for the Removal of Ammonia in Wastewater. Process Safety and Environmental Protection. 122: 378-385.

Doi:10.1016/J.PSEP.2018.12.00 3.

[77] C. Ren, H. Fang, J. Gu, L. Winnubst, C. Chen. 2015. Preparation and Characterization of Hydrophobic Alumina Planar Membranes for Water Desalination. Journal of the European Ceramic Society. 35: 723-730.

Doi:10.1016/J.JEURCERAMSO C.2014.07.012.

[78] P. Xu, Z. Jin, T. Zhang, X. Chen, M. Qiu, Y. Fan. 2021. Fabrication of a Ceramic Membrane with Antifouling PTFE Coating for GasAbsorption Desulfurization. Industrial \& Engineering Chemistry Research. 60: 24922500.

Doi:10.1021/ACS.IECR.1C0033 8.
[79] Z. Cui, E. Drioli, Y. M. Lee. 2014. Recent Progress in Fluoropolymers for Membranes. Progress in Polymer Science. 39: 164-198.

Doi:10.1016/J.PROGPOLYMSC I.2013.07.008.

[80] J. Pan, X. Xu, Z. Wang, S.-P. Sun, Z. Cui, L. Gzara, I. Ahmed, O. Bamaga, M. Albeirutty, E. Drioli. 2021. Innovative Hydrophobic/hydrophilic

Perfluoropolyether

(PFPE)/polyvinylidene Fluoride (PVDF) Composite Membrane for Vacuum Membrane Distillation. Chinese Journal of Chemical Engineering. Doi:10.1016/J.CJCHE.2021.03.0 18.

[81] H. Yan, X. Lu, C. Wu, X. Sun, W. Tang. 2017. Fabrication of a Super-hydrophobic Polyvinylidene Fluoride Hollow Fiber Membrane using a Particle Coating Process. Journal of Membrane Science. 533: 130140.

Doi:10.1016/J.MEMSCI.2017.03 .033 .

[82] H. Ke, E. Feldman, P. Guzman, J. Cole, Q. Wei, B. Chu, A. Alkhudhiri, R. Alrasheed, B. S. Hsiao. 2016. Electrospun Polystyrene Nanofibrous Membranes for Direct Contact Membrane Distillation. Journal of Membrane Science. 515: 8697.

Doi:10.1016/J.MEMSCI.2016.05 .052 .

[83] D. Hou, D. Lin, C. Ding, D. Wang, J. Wang. 2017. Fabrication and Characterization of Electrospun Superhydrophobic PVDFHFP/SiNPs Hybrid Membrane for Membrane Distillation, Separation and Purification Technology. $\quad$ 189: $\quad 82-89$. 
Doi:10.1016/J.SEPPUR.2017.07. 082.

[84] L. D. Tijing, J.-S. Choi, S. Lee, S.-H. Kim, H. Kyong Shon. 2014. Recent Progress of Membrane Distillation using Electrospun Nanofibrous Membrane.

Doi:10.1016/j.memsci.2013.11.0 22.

[85] K. Li, D. Hou, C. Fu, K. Wang, J. Wang. 2018. Fabrication of PVDF Nanofibrous Hydrophobic Composite Membranes Reinforced with Fabric Substrates via Electrospinning for Membrane Distillation Desalination. Journal of Environmental Sciences. 75: 277-288.

Doi:10.1016/j.jes.2018.04.002.

[86] J. Li, L.F. Ren, J. Shao, Y. Tu, Z. Ma, Y. Lin, Y. He. 2020. Fabrication of Triple Layer Composite Membrane and Its Application in Membrane Distillation (MD): Effect of Hydrophobic-hydrophilic

Membrane Structure on MD Performance. Separation and Purification Technology. 234: 116087.

Doi:10.1016/J.SEPPUR.2019.11 6087.

[87] N. A. Ahmad, P. S. Goh, L. T. Yogarathinam, A. K. Zulhairun, A. F. Ismail. 2020. Current Advances in Membrane Technologies for Produced Water Desalination. Desalination. 493: 114643. Doi:10.1016/j.desal.2020.114643

[88] M. Rezaei, D. M. Warsinger, J. H. Lienhard V, M. C. Duke, T. Matsuura, W. M. Samhaber. 2018. Wetting Phenomena in Membrane Distillation: Mechanisms, Reversal, and Prevention. Water Research. 139: 329-352.
Doi:10.1016/J.WATRES.2018.0 3.058 .

[89] S. Al-Gharabli, Z. A. El-Rub, E. Hamad, W. Kujawski, Z. Flanc, K. Pianka, J. Kujawa. 2021. Surfaces with Adjustable Features-Effective and Durable Materials for Water Desalination. International Journal of Molecular Sciences. 22: 11743. Doi:10.3390/IJMS222111743.

[90] M. Mozetič 2019. Surface Modification to Improve Properties of Materials. Materials. $\quad$ 12: 441. Doi:10.3390/MA12030441.

[91] S. Rabiei, S. M. Mousavi, A. H. J. Paterson. 2020. Development of Hierarchical Surface Roughness on Porous Poly (Vinylidene Fluoride) Membrane for Membrane Distillation Process. Polymer Engineering \& Science. 60: 1686-1698. Doi:10.1002/PEN.25412.

[92] B. J. Deka, J. Guo, N. K. Khanzada, A. K. 2019. An, Omniphobic Re-entrant PVDF Membrane with $\mathrm{ZnO}$ Nanoparticles Composite for Desalination of Low Surface Tension Oily Seawater. Water Research. 165 : 114982. Doi:10.1016/J.WATRES.2019.1 14982.

[93] G. Barati Darband, M. Aliofkhazraei, S. Khorsand, S. Sokhanvar, A. Kaboli. 2020. Science and Engineering of Superhydrophobic Surfaces: Review of Corrosion Resistance, Chemical and Mechanical Stability. Arabian Journal of Chemistry. 13: 1763-1802. Doi:10.1016/J.ARABJC.2018.01 .013 .

[94] A. Razmjou, E. Arifin, G. Dong, J. Mansouri, V. Chen. 2012. Superhydrophobic Modification of $\mathrm{TiO} 2$ Nanocomposite PVDF 
Membranes for Applications in Membrane Distillation. Journal of Membrane Science. Doi:10.1016/j.memsci.2012.06.0 04.

[95] D. Grosso. 2011. How to Exploit the Full Potential of the DipCoating Process to Better Control Film Formation. Journal of Materials Chemistry. 21: 17033-17038.

Doi:10.1039/C1JM12837J.

[96] I. Jesswein, S. Uebele, A. Dieterich, S. Keller, T. Hirth, T. Schiestel. 2018. Influence of Surface Properties on the Dip Coating Behavior of Hollow Fiber Membranes. Journal of Applied Polymer Science. 135. Doi:10.1002/APP.46163.

[97] P. Zhang, W. Liu, S. Rajabzadeh, Y. Jia, Q. Shen, C. Fang, N. Kato, H. Matsuyama. 2021. Modification of PVDF Hollow Fiber Membrane by Codeposition of PDA/MPC-coAEMA for Membrane Distillation Application with Anti-fouling and Anti-scaling Properties. Journal of Membrane Science. $\quad 636$ : 119596. Doi:10.1016/J.MEMSCI.2021.11 9596.

[98] H. K. Lee, B. M. Jun, S. S. Ray, Y. N. Kwon. 2021. ThreeLayered Hollow Fiber (HF) Membrane and Its Modification to Enhance Wetting Resistance for Membrane Distillation (MD). Environmental Technology \& Innovation. $\quad 21$ : 101227. Doi:10.1016/J.ETI.2020.101227.

[99] M. M. A. Shirazi, D. Bastani, A. Kargari, M. Tabatabaei. 2013. Characterization of Polymeric Membranes for Membrane Distillation using Atomic Force Microscopy. New Pub: Balaban. 51: 6003-6008. Doi:10.1080/19443994.2013.765
365.

[100] Y. Alqaheem, A. A. Alomair. 2020. Microscopy and Spectroscopy Techniques for Characterization of Polymeric Membranes. Membranes. 10: 33. Doi:10.3390/MEMBRANES100 20033.

[101] M. Tian, S. Yuan, F. Decaesstecker, J. Zhu, A. Volodine, B. Van der Bruggen. 2020. One-step Fabrication of Isotropic Poly(Vinylidene Fluoride) Membranes for Direct Contact Membrane Distillation (DCMD). Desalination. 477: 114265.

Doi:10.1016/j.desal.2019.114265

[102] K. He, H. J. Hwang, M. W. Woo, I. S. Moon. 2011. Production of Drinking Water from Saline Water by Direct Contact Membrane Distillation (DCMD). Journal of Industrial and Engineering Chemistry. 17: 4148.

Doi:10.1016/J.JIEC.2010.10.007.

[103] S. Dinarelli, M. Girasole, G. Longo. 2018. FC_Analysis: A Tool for Investigating Atomic Force Microscopy Maps of Force Curves. BMC Bioinformatics. 19: 1-12. Doi:10.1186/S12859-0182265-4.

[104] H. Öktem, T. Erzurumlu, H. Kurtaran. 2005. Application of Response Surface Methodology in the Optimization of Cutting Conditions for Surface Roughness. Journal of Materials Processing Technology. 170: 1116.

Doi:10.1016/J.JMATPROTEC.2 005.04.096.

[105] S. Parvate, P. Dixit, S. Chattopadhyay. 2020. Superhydrophobic Surfaces: Insights from Theory and Experiment. The Journal of Physical Chemistry B. 124: 
1323-1360.

Doi:10.1021/ACS.JPCB.9B0856 7.

[106] S. S. Latthe, C. Terashima, K. Nakata, A. Fujishima. 2014. Superhydrophobic Surfaces Developed by Mimicking

$\begin{array}{lrr}\text { Hierarchical } & & \text { Surface } \\ \text { Morphology of Lotus } & \text { Leaf, } \\ \text { Molecules. } & 19: & 4256 . \\ \text { Doi:10.3390/MOLECULES1904 } \\ \text { 4256. }\end{array}$

Hierarchical Surface Morphology of Lotus Leaf, Molecules. $\quad 19$ : 4256. 4256. 